\title{
O Trabalho, a Competência, a Organização e a Importância dos Objetivos, em uma Nova Lógica da Dinâmica Funcional
}

\section{The Work, The Ability, The Organization And The Importance Of The Objectives, In A New Logic Of The Functional Dynamics}

\author{
Mario Arthur de Souza Fontes ${ }^{1}$ \\ Agamêmnom Rocha Souza ${ }^{2}$
}

\section{Resumo}

Este estudo irá estabelecer a conceituação básica para uma organização, tão necessária ao sucesso do processo de comunicação organizacional, bem como, irá enfatizar a importância do objetivo de consenso claro e próprio à organização para o atingir de suas metas. Proporcionará uma visão sistêmica de aplicação a uma organização. $\mathrm{E}$, finalmente, fazer entender, que todas as organizações, sejam quais forem os setores de sua atuação, têm de enfrentar os efeitos das rápidas transformações, dos novos concorrentes e das mudanças de perfil e da fidelidade dos seus ditos clientes.

Palavras-chave: organização, conceituação, comportamento.

\begin{abstract}
This study it will go to establish the basic conceptualization for an organization, so necessary to the success of the process of organizational communication, as well as, will go to emphasize the importance of the objective of and clearly proper consensus to the organization, to reach it of its goals. It will provide a systems vision of application to an organization. The finally, to make to understand, that all the organizations, whichever the sectors of its performance, have to face the effect of the fast transformations, the new competitors and the changes of profile and the allegiance of its said customers.
\end{abstract}

Key-Words: organization, conceptualization, behavior.

\author{
1 Mestre \\ mario.fontes@foa.org.br \\ 2 Mestre \\ agamemnom.souza@foa.org.br
}




\section{Introdução}

Ao vivenciarmos estes tempos de mudanças, abrangentes, velozes, espantosas, quando tudo muda e muda, muitas vezes sem que a maioria dos atores do processo, sequer tome consciência dessa mudança. Assim, muda-se com freqüência, a maneira como nos relacionamos com as pessoas; o modo como conduzimos as nossas atividades, profissionais e até, pessoais; o enfoque que damos ao trabalho, a competência e a organização, especialmente no que tange a reconhecer a importância dos clientes e procurando atender às necessidades e expectativas.

Tudo muda; inclusive os procedimentos e as técnicas as quais empregamos para o adequado gerenciamento de nossas organizações. Teorias que até "ontem" eram tidas como práticas usuais, colocadas em prática hoje, sem adequada flexibilidade, podem levar as organizações à concordata e ao desaparecimento.

O que dizer então da importância das decisões em consenso para as organizações? Em destaque e, exatamente neste momento, você que está lendo este artigo, decidiu mais uma vez dentre os milhares de decisões que toma. É isso, porque vivemos todos em uma esfera de enfrentamento dos desafios em inúmeras áreas, circunstâncias e tempo, sempre agindo de modo a atender determinados objetivos organizacionais. Resolver problemas, atingir objetivos, tudo isso só é possível mediante o seu conhecimento dessa nova lógica, e observe ainda que sempre teremos várias alternativas para a decisão, por este ou aquele caminho, capaz de ajudar a resolver o problema ou a atingir os objetivos.

A estes caminhos, pode-se, neste ponto, chamar-se de "estratégias". Ocorre que, para podermos analisar os prós e os contras de cada alternativa, de cada estratégia, necessitamos de informações formais ou não. Esse é o campo, o assunto primordial deste trabalho, a contribuição para que você possa, cada vez melhor, tomar as suas direções ao evento, posição esta de caráter pessoal ou profissional, dentro de sua organização.

Em outras palavras, com este artigo, procuraremos contribuir positivamente para todo aquele que possa reunir em si mesmo e na sua formação, especialização ou reciclagem, os três pontos básicos para o sucesso profissional em sua organização:
- Aquisição de conhecimento sobre as técnicas profissionais, relacionadas ao tema do artigo;

- Conhecimento sobre a estruturação das organizações e de negócios; e

- Compreensão adequada de como as pessoas se comportam em organizações.

$\mathrm{Na}$ verdade, esses conhecimentos são necessários porque não lideramos, gerenciamos, supervisionamos ou chefiamos equipamentos e tecnologias, mas sim pessoas, seres humanos.

Espera-se que o artigo possa auxiliar a sensibilizar àquele que deseja obter e/ou manter o sucesso pessoal e profissional, cumprindo os deveres e as atribuições de um verdadeiro líder, que deve ser uma pessoa adequadamente capacitada e, principalmente, respeitosa e ética ao administrar pessoas de uma organização.

\section{O sistema organização}

Como máxima temos: “é impossível a qualquer pessoa viver sozinha". Segundo regras, somos essencialmente, seres sociais e sabe-se que nem mesmo os ditos "eremitas" conseguem ficar sozinhos e sempre procuram estar acompanhados de outros seres vivos, sejam eles animais ou vegetais. Assim sendo, o ser humano sempre procura se associar a outros seres humanos para atingir os seus objetivos, partindo do principal e básico a "sobrevivência" de tudo que o rodeia.

Os seres humanos, desde as eras pré-históricas, se organizam em comunidades, equipes, etc. com vistas à proteção mútua e à obtenção de alimentos, tudo visando à sobrevivência e entendendo por "organização" a indicação clara das tarefas e atribuições de cada componente do conjunto. Com base nestas verdades históricas, cremos poder chegar ao seguinte conceito para uma organização:

"um agrupamento de seres humanos, uma organização humana, com atribuição de atividades e de responsabilidades entre os vários seres que a constituem, de modo que se possa atingir objetivos pré-determinados". 
Desde o surgimento da primeira organização, o homem vem desenvolvendo tecnologia, na forma de técnicas, métodos e equipamentos para poder cumprir mais adequadamente suas atribuições. O que ocorreu com os primeiros feiticeiros da pré-história será um bom exemplo, pois tinham eles a responsabilidade dupla de por um lado, interceder pela tribo aos deuses primitivos e, por outro, defendê-la das iras dos deuses. Ora, para cumprir melhor com suas atribuições, eles foram desenvolvendo vestimentas, máscaras, rituais, instrumentos, etc..., à semelhança dos seres humanas atuais, que se utilizam de métodos e processos definidos e se utilizaram de recursos computacionais e mesmo da robótica para melhorar o desempenho de suas tarefas, não é a verdade?.

Agora, podemos concluir que, em qualquer época, os seres humanos sempre necessitam de:

- definir claramente os objetivos a atingir;

- desenvolver planejamento para viabilizá-lo;

- organizar tudo como o plano estabelecido oferece;

- preparar as ações, pois sem elas não haverá reação, não haverá resultados;

- comandar e coordenar sempre estas operações para o sucesso dos resultados;

- controlar o desempenho e logicamente avaliar os resultados obtidos.

Graças ao processo de avaliação dos resultados é que podemos determinar a necessidade ou não de alteração de planos da organização dos recursos e, até mesmo, dos próprios objetivos.

Será demonstrado no Quadro 1. a seguir, que a tarefa de controle e avaliação não é, nem deve ser executada como atribuição estática e final. Trata-se de um processo que deve ser medido continuamente, durante a realização de cada tarefa e, consoante às modernas técnicas de que a gestão deve ser responsável. O ser humano é que gera qualidade no ato da realização de suas ações e não mais como era conceito antigo, deixar a cargo de uma área de "controle" ,verificar a qualidade dos serviços e produtos decorrentes de cada tarefa.

Genericamente, uma organização é uma reunião de recursos, visando atender um dado objetivo, por isso a definição: "uma organização é uma entidade jurídica que tem como obrigação apresentar lucro, lucro este suficiente para permitir sua expansão e o atendimento das necessidades sociais".

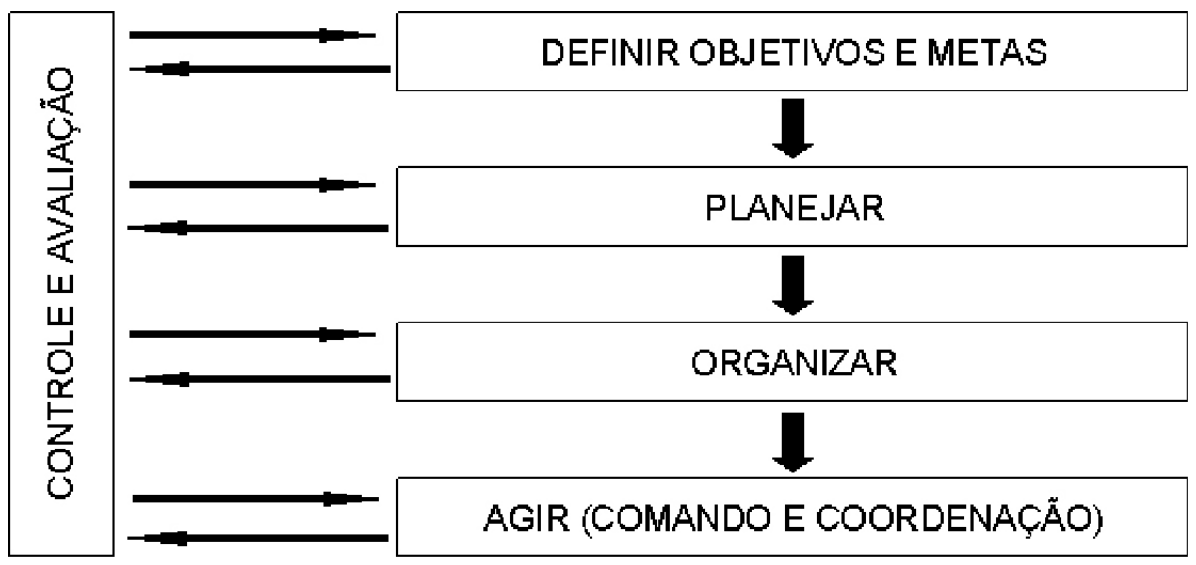

QUADRO 1 - Sistema de informações para tomada de posição

Todavia, o maior objetivo de qualquer organização é o adequado atendimento de sua comunidade, de sua clientela. Só assim é que ela poderá gerar negócios lucrativos, perpetuando a existência da organização. Parece óbvio, mas não é; uma organização apenas poderá ter sucessos se existir:

- uma conceituação clara do objetivo a ser atendido;

- um planejamento global e uma organização tal que permitam, mediante o emprego dos recursos necessários, cumprir o objetivo; e

- uma sistemática de controle prevista e determinada pelo planejamento, capaz de medir os resultados reais contra os planejados e, mediante um sistema correto de feedback, possibilitar a adoção de medidas necessárias à correção de possíveis desajustes.

Tudo isso implica que haja clara definição do objetivo social e do ramo de atividade da organização, 
uma estruturação adequada e a alocação correta de cada um dos recursos necessários.

Toda e qualquer organização, por menor ou maior que seja, de qualquer ramo de atividade, é um sistema e pode ser representado no fluxograma Quadro 2 abaixo:

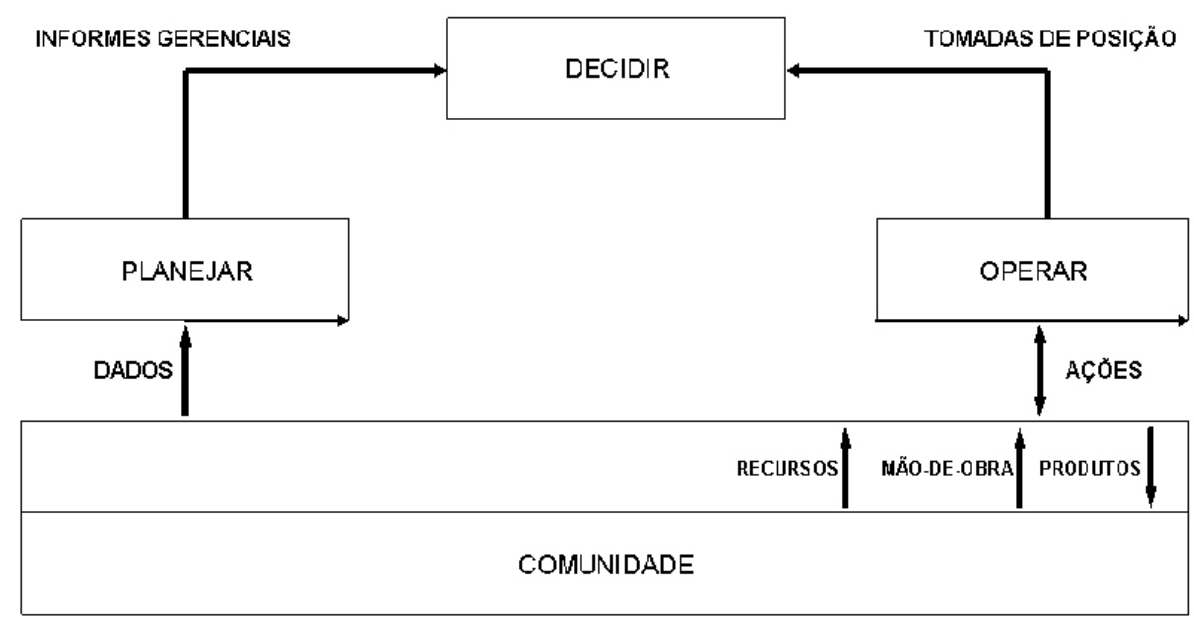

QUADRO 2 - Fluxograma do macro-sistema

A organização, além de seus recursos, também obtém da comunidade os recursos necessários como mão-de-obra, retorno de capital e etc..., lhe atendendo as necessidades, mediante o fornecimento de produtos. Desta integração empresa/mercado, provêm os dados básicos, para junto aos dados operacionais da organização, possibilitar a análise de desempenho, o planejamento e sua atualização, assim realimentando o ciclo de planejar, decidir e operar. Há que se considerar a importância dessa visão empresarial para o sucesso, o que será melhor detalhado um pouco mais, o que isto representa e quer demonstrar:

- toda e qualquer organização se apóia na "comunidade" que constitui o seu mercado e os responsáveis pela organização, como os diretores, gerentes, supervisores, que necessitam levantar e analisar o mercado para saber se omercado demanda ou não dos produtos que são fornecidos a este mercado. Se houver a demanda, há que se considerar se a mesma é ou não economicamente viável, se compensará, financeiramente ou se a organização deve se estruturar para fornecer o produto e ainda considerar o quanto custará esta estruturação;

- baseado nos dados obtidos durante a pesquisa e a análise do mercado, poder "planejar" e, graças a isso, prestar informações aos responsáveis, aos diretores, gerentes, supervisores e etc..., de modo que eles possam, adequadamente, "decidir" a favor ou contra a estruturação da organização. E estas posições irão colocar ou não a organização em "opera- ção", dependendo é claro, dos responsáveis como foi dito;

- o verbo "operar", nesse caso, implica o entendimento desde a construção da fábrica até a aquisição e montagem dos equipamentos, a contratação de pessoal, a aquisição de serviços e de bens, em suma, tudo o que for necessário para que a organização tenha condições de operar. Observando que as operações da organização constituem um intercâmbio permanente com a sua comunidade. Por um lado, o oferecimento dos produtos e por outro, retirando todos os recursos de que necessita, como pessoal, matéria-prima, financiamentos e etc...;

- a partir desse ponto, será fácil demonstrar que duas modalidades básicas de informações devem continuamente ser produzidas, quais sejam:

- as relativas aos levantamentos e análise de mercado - como o mercado está reagindo frente aos serviços e /ou produtos oferecidos, uma vez que o cliente é de fato, o foco da organização, por isso é importante identificar com clareza essas reais necessidades, pois daí parte o ensejar o desenvolvimento/alteração do produto, ou até mesmo a sua eliminação,

- as relacionadas diretamente às operações da organização - como as aquisições de mercadorias, contratação dos serviços, a industrialização, a manutenção industrial, a comercialização, a distribuição, o marketing, finanças e etc... . 
Estes dois conjuntos de informações são os que permitirão, de um modo adequado, rever nossos planos, redirecionar a aplicação de recursos, permanecer, expandir ou sair do mercado, etc..., isto é gerir, administrar adequadamente a organização. Pode-se representar esta indicação conforme o fluxograma (Quadro 3) que se segue:

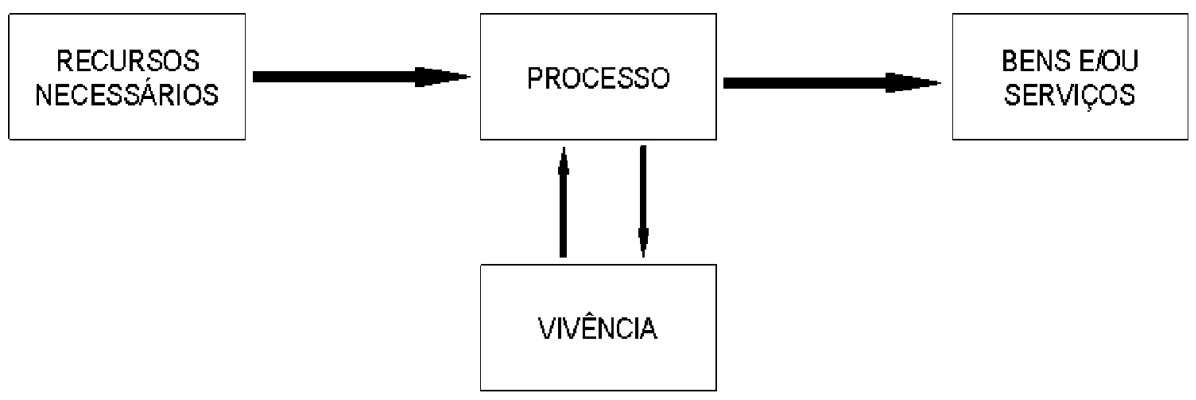

QUADRO 3 - Fluxograma de visão do macrossistema

$\mathrm{Na}$ verdade, ingressam na organização uma gama de recurso que sofre um determinado arranjo e transformação, mediante a aplicação de um determinado processo, que geram bens e/ou serviços que são ofertados ao mercado. E da realização deste processamento, surge uma vivência que é consultada a cada ciclo do processo, consoante sugere o Quadro 4, que adiante se vê.
É muito importante que se memorize esta representação, pois será vista em outra oportunidade, quando analisarmos mais profundamente sobre os sistemas de informações. Aqui, estará apenas representando um conceito genérico da organização e não todo e qualquer sistema componente da organização. Um dos modos clássicos de representação de uma organização está no fluxo a seguir disposto:

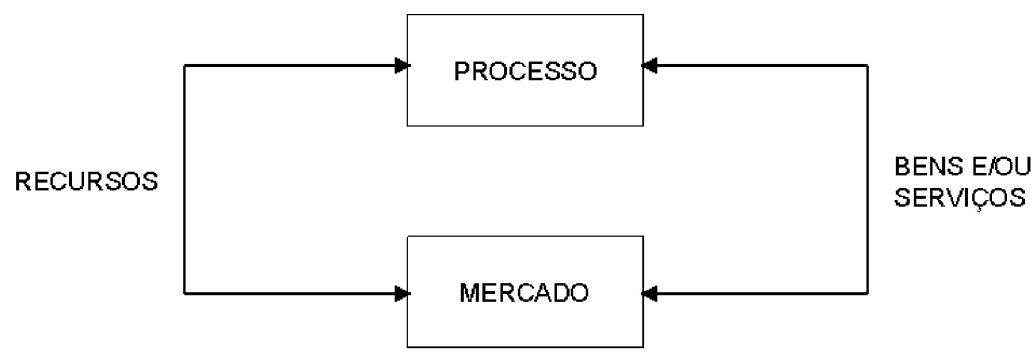

QUADRO 4 - Fluxograma de organizações

Convém salientar, ainda, que não existe uma organização estática. Todas são dinâmicas. O que ocorre é que a direção deste dinamismo poderá variar de positiva a negativa. Positivamente, implicando o crescimento das operações, na diversificação das atividades, na maior lucratividade e etc... Negativamente, corresponde à diminuição dos níveis de operações, na redução de pessoal nas atividades e na redução de produtos fabricados e etc..., podendo causar até o fechamento do negócio ou o encerramento das operações da organização. E, este comportamento organizacional, é o principal componente gerado pelos seres humanos que compõem a organização, desde o mais alto escalão, até o mais humildes dos servidores. Portanto, sem sombra de dúvidas o que torna uma organização mais dinâmica, mais capaz, mais aguerrida do que uma outra é o ser humano que a integra.

\section{A importância de estabelecer os objetivos}

Todos os seres humanos concordam que a definição clara de objetivos é muito importante, mas, desafortunadamente, poucos seres humanos definem realmente os seus objetivos. Talvez, por isso, em sua grande maioria, as pessoas tão pouco se realizam durante sua vida de trabalho. Existem estudos que procuram demonstrar que, em média, os seres humanos não utilizam mais do que $15 \%$ de sua capacidade, ao longo de toda a sua vida. E, uma das principais causas é, sem dúvida, a não definição clara de objetivos. Há que se crer, não haver discordância de que não existem organizações sem objetivos e ou sem finalidades.

$\mathrm{Na}$ verdade, o que ocorre, na maioria dos casos, é que, nem sempre, esses objetivos estão formalizados e essa não-formalização contribui negativamen- 
te para o sucesso empresarial.

Academicamente, poder-se-ia até formalizar a pergunta: o que é um objetivo? O que é uma meta? Há diferença entre um objetivo ou uma meta?

Somos de opinião que devemos começar a responder a última pergunta, ou seja: SIM, existe uma clara diferença entre os dois. Uma diferença de nível! O objetivo diz respeito aos grandes propósitos da organização, envolvendo-a toda; a meta, apesar de ter uma parte do objetivo, tem um nível divisional, departamental.

Alguns estudiosos definem que: "objetivo é o grande propósito da organização e se expande; quebra-se em metas; estas, sim, são partes do objetivo, pois são divisionais" e outros definem que: "metas sim, que são o grande propósito da administração. Objetivos, são partes menores da meta, isso sim". De qualquer modo a verdade é que existe uma clara diferença de níveis. Entendemos que os "objetivos" são os grandes propósitos da organização e que "metas", são suas partes menores, seus detalhes. Mesmo assim, é de bom alvitre deixar, neste artigo, uma definição menos conflitante:

“Objetivo/metas são propósitos claramente redigidos e adequadamente quantificados"

Explicando esses porquês: claramente redigido - para que haja clara compreensão. Agora, não deve pairar dúvidas ao que desejamos que seja alcançado e adequadamente quantificado - para que se possa medir, avaliar, e comparar os resultados.

Finalizamos com estas discussões sobre o que encerra um objetivo e o que prepara uma meta.

"Sabedoria é saber o que fazer, mas a virtude está em fazer".

Economista David S. Jordan

\section{Como estabelecer objetivos}

Muitas pessoas perguntam e sempre têm a mesma dúvida, ficando a perguntar: " mas como poderemos estabelecer objetivos"? "Sempre vivemos a perguntar sobre eles, mas na verdade nunca nos foi detalhado o como fazer?". Logicamente, esta dúvida também nos acompanhou por muitos anos. Tanto é verdade, que existe uma grande quantidade de obras sobre Administração e Gerência que desenvolveram temas somente sobre "objetivos", mas também é verdade que, outras poucas se preocupavam em estabelecer e divulgar o COMO. Por isso o preparar desse artigo, onde se seguirá um método simples, que poderá ser de grande utilidade. Primeiramente ao se pensar em termos de objetivos pessoais, poder-se-á desenvolver objetivos profissionais, culturais, financeiros e através das seguintes etapas:

- Etapa 1 - PENSE claramente no que deseja alcançar ou em que ponto deseja aprimorar sua capacitação;

- Etapa 2 - Uma vez esboçada sua intenção, seu objetivo, ESCREVA o mais claramente possível o que deseja alcançar, o seu objetivo;

- Etapa 3 - Leia cuidadosamente o que escreveu. Agora QUANTIFIQUE em quanto tempo deseja alcançar, "mas seja realista", outros parâmetros numéricos, podem ser estimados, como quantidade, $\%$, valor e etc...;

- Etapa 4 - Detalhe as ETAPAS, ou seja, as fases que deverão ser percorridas até que você alcance o seu objetivo.

- Etapa 5 - E, principalmente, indique claramente $\mathrm{O}$ QUE DARÁ EM TROCA ao atingir esse objetivo.

Nunca se pode esquecer de que nada é gratuito, tudo exige uma paga e, neste caso, ela poderá ser o dar o melhor de si para o sucesso da organização na qual você venha a desempenhar as funções comerciais, conduzindo seus procedimentos e sempre dentro da ética, da moral profissional. Tentar-se-á resumir abaixo em um fluxo simples e prático o que deve ser preparado, consubstanciado no Quadro 5.

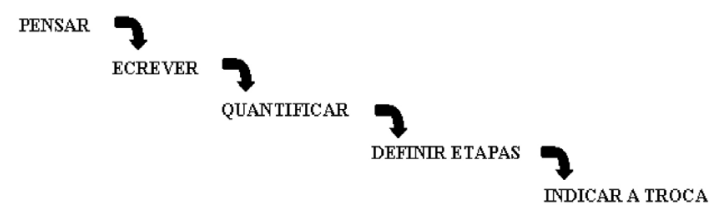

QUADRO 5 - Degraus para definir objetivos 
Esperamos que tenha ficado claro, visto que se pode ter, nas coisas simples, a grande oportunidade de preparar e gerenciar os objetivos e as metas de uma organização da qual se gosta e que se deseja ver em sucesso.

Nota: Revise periodicamente seus objetivos traçados, preste atenção nas metas e não se esqueça de fazê-lo, pelo ao menos uma vez por ano, durante toda a sua vida de organização.

\section{Considerações Finais}

Fez-se questão em manter neste artigo, o que sempre foi pensado mas, por sua simplicidade, nunca escrito. É que ,na verdade, em Administração, o gerenciamento é a etapa de partida de tudo. Pensando assim, antes de se iniciar nos objetivos e metas, como foi visto ser definido e acompanhado pela Alta Administração e tendo na gerência a supervisão desse acompanhamento do operacional qual seja: o sistema! Que é composto de recursos humanos, administração geral, planejamento, controle da produção, suprimentos, manutenção, desenvolvimento de produto e de mercado, propaganda e promoção, vendas, distribuição, contabilidade, orçamento e custos, financeiro, tesouraria, organização e métodos e processamento de dados.

Por isso se deseja a leitura do artigo, com a maior atenção e avaliação, até porque tem visão prática e a grande maioria das funções necessárias ao diaa-dia da comunidade e da organização.

Foi ressaltado, ao longo deste artigo, o fato que os seres humanos são as molas propulsoras das organizações, até porque estas existem para o atendimento das necessidades das organizações e não devem sair do conceito de que, as pessoas eficientes são aquelas presas em normas, políticas e procedimentos estabelecidos; enquanto que a pessoa eficaz não se prende tanto a normas, políticas e procedimentos. Estas objetivam, primordialmente, a obtenção de resultados, motivo destes estudos para o artigo que ora encerramos, muito embora sua temática seja infinda. 


\section{Referências}

ADIZER, Ichak. Gerenciando Mudanças - O poder da confiança e do respeito mútuo. São Paulo: Pioneira, 2006.

ALVES, Sérgio. Revigorando a Cultura da Empresa - Uma abordagem cultural da mudança nas organizações na Era da Globalização. São Paulo: Pioneira, 2004.

BLANCHARD, Ken. e WAGHORN, Terry. Missão Possível-Como tornar sua organização "Classe Mundial" enquanto é tempo. São Paulo: Makron Books, 2005.

DRUCKER, Peter F. As novas realidades - Administrando para o futuro - A nossa Era da administração. São Paulo: Pioneira, 2005.

GIBSON, Rowan. Repensando o Futuro - Negócio, Estratégia, Concorrência, Controle, Liderança, Mercados, Globalização. São Paulo: Makron Books, 2005.

HANDY, Charles. A Era da Transformação - A transformação do mundo das organizações. São Paulo: Makron Books, 2006.

PEREIRA, Maria J. L. Bretas e MARQUES, J. G. F. Faces da Decisão - As mudanças de paradigma e poder da decisão. São Paulo: Makron Books, 2004.

ZARIFIAN, Philippe. Objetivo Competência - por uma nova lógica. São Paulo: Atlas, 2007.

\section{Informações bibliográficas:}

Conforme a NBR 6023:2002 da Associação Brasileira de Normas Técnicas (ABNT), este texto científico publicado em periódico eletrônico deve ser citado da seguinte forma:

FONTES, M. A. S.; SOUZA, A. R. O Trabalho, a Competência, a Organização e a Importância dos Objetivos, em uma Nova Lógica da Dinâmica Funcional. Cadernos UniFOA, Volta Redonda, ano II, n. 4, agosto. 2007. Disponível em: <http://www.unifoa.edu.br/pesquisa/caderno/edicao/04/64.pdf $>$ 